\title{
Making Money: Financial Literacy as an Object of Governance
}

\author{
Michael Christie \\ Professorial Research Fellow \\ Northern Institute \\ Charles Darwin University \\ michael.christie@cdu.edu.au
}

Keywords: Objects of governance, Aboriginal, financial literacy, Yolnu

\section{The objects of my research}

I had been told a couple of times that I had to clear out from the university server, a great mass of computer files from previous research projects - gigabytes of notes, videos, spreadsheets, ethics applications, reports, notes and reflections - associated with different projects over the years, all rather badly organised. Working in a relatively new, relatively remote Australian university, I enjoy being relatively unencumbered by academic traditions, but am suddenly constrained by the limits of our technology and my ability to use it. I must put all the files on a 'USB Pen Drive' and take them to 'Records and Archives' for storage. Then I must wipe the V: drive. If I want any archived file, I can walk down to 'Records \& Archives' with a memory stick and request a copy.

It is a strange feeling looking through all those files. They contain traces of so much interesting work undertaken since the computer server was introduced to store the objects of our work. There was a tinge of pride in all the complex collaborative work I had undertaken with Yolnu Aboriginal people, and with colleagues and government workers, but that pride was spoilt by the feeling that so much of the material has remained unexamined, and never retold or reworked, and worse, that so many of the papers and reports - mostly to governments but also to industry and NGOs - really didn't lead to much change on the ground. We seem to have been given more and more work over the past twenty years, with those who fund the research paying less and less attention to what we produce.

In my cleaning work, I spotted a folder called 'Financial Literacy Evaluation 2008'. Our crosscultural consultancy group, which we called the Yolnu Aboriginal Consultancy Initiative, had been asked to evaluate a program of Financial Literacy training for a small credit union based in the Northern Territory (which I'll call 'Small Bank'), dedicated to serving the financial needs of remote Aboriginal communities. The evaluation was being funded by a major national financial institution (which I'll call 'Big Bank') as part of its commitment to 'reconciliation'1. I began to piece back together in my mind why and how we had been invited to undertake this consultancy as I, pretty much randomly, opened up the most interesting-sounding files in what turned out to be a large trove of documents.

There were a few objects that set me thinking. One was the folder of power point presentations developed for Indigenous Financial Literacy, by various government and nongovernment organisations with names like 'MoneyMinded' and 'MoneyBusiness', and adapted for local delivery. The PowerPoints were very attractive, with cartoons of men saving for cars, and 
women for washing machines. Bespoke budgeting slides invited participants to estimate how much money they spent per week on board, cigarettes, fares, 'grog', takeaways, CDs, 'ganja', clothes and the chemist, followed by an example of 'Tony's new weekly budget' after deciding to go on a 'SMART' (that is Specific, Measureable, Achievable, Realistic, and Timed) budget by reducing selected weekly estimates. I remember having marveled at their slick graphics back in 2008 , looking forward to finding out what the Yolnu clients had made of them as we undertook the program evaluation.

Another folder contained our final report to the Big Bank which detailed the process, and which can be found with a couple of short videos, on the Yolnu Aboriginal Consultants Initiative website ${ }^{2}$. These brought to surface memories of wonder, delight and frustration at the complex ways the project unfolded and then, in time, disappeared.

After our Objects of Governance workshop, I began trying to think of Financial Literacy as an object of governance. In Foucault's (2009) terms, both banks could be seen as exercising pastoral-care over Aboriginal clients, a form of care which was taken on as a duty of beneficence while at the same time increasing Big Bank's standing as a good corporate citizen and Small Bank's reach and profits.

What I want to explore in this paper is the ways in which our Yolnu co-researchers handed the process of evaluation and reporting back to the banks, and how their participation and method revealed to me a keen Yolnu insight into the governmentality that produced the bank and its practices and clients, and what must be done to develop agreed ways forward for a better practice.

\section{Financial Literacy as an Object of Governance}

As I began my search for an analytic thread, I developed a sense that there are in fact two different monies running through this story. One money was the Aboriginal money imagined by the banks. The financial literacy training materials made quite a deal of the fact that money was an alien thing in Aboriginal society (with graphics of traditional exchange practices contrasted with the arrival of money and its institutions). But to the Yolngu, money is a very significant participant in the everyday practices of community life. The only thing alien about it is the attitudes and practices of the banks. Where did the banks imagine 'Aboriginal money' comes from and what assumptions and practices did it bring with it? I searched for some background in the literature, and found that Wikipedia like many other sources, treated Financial Literacy as already existing, fully formed, a need for people who are 'financially excluded' and a responsibility for governments and financial institutions to address. Both Big Bank and Small Bank were sufficiently committed to Financial Literacy in remote communities that they invested in an evaluation of their community training program. They wanted value for money. We were asked to evaluate the program, not to research Financial Literacy, but as so often happens, as soon as the Yolnu consultants became involved, they immediately addressed the whole concept and practice of Financial Literacy and its training regime as an object of governance being visited upon their world. Only after the workshop with Helen Verran (another author in this issue), and some time alone with Foucault (2009), could I see it that way.

Financial Literacy, I discovered with some further research, had come out of the notion of 'Financial Exclusion', one of the 'profound economic and social consequences' (Leyshon \& Thrift, 1995, p.312) of financial crises. So here was my first clue. The financial literacy project came from a commitment on the part of Big Bank, one of Australia's major financial institutions, 'to contribute to increased financial and social well-being for Aboriginal and Torres 
Strait Islander peoples ... (to) reflect our corporate responsibility priorities and our approach to respecting human rights' (ANZ Indigenous Action Plan, 2011/2014).

Implicit in the Big Bank Indigenous Action Plan (in its various versions) is the double goal of a) increasing 'financial inclusion' of Indigenous people through b) increasing the uptake by Indigenous people of their financial 'products'. The first goal of the small bank's Financial Literacy project is 'to increase the capacity of ... members to more fully participate in the developing economic base of their communities' (ANZ-Traditional Credit Union, 2008, p.37).

I began to see Financial Literacy not as a human capacity but more as a program. That is the Big Bank is funding the Small Bank to educate the remote Aboriginal population in 'the knowledge and skills required for effective money management'. But at the same time, to engage them with their 'financial products'. So it is in fact a double project, bundled up tightly and polished to hide its fault lines (if not its duplicity), and presented and worked with as selfevident, with no history, and no agenda.

Financial Literacy in its manifestation as a community education program constitutes the banking services and its customers as particular sorts of subjects and objects. One perspective has it emerging as a solution to a crisis, but in another it seems to be creating a crisis, or spreading the domain of a crisis to include remote Aboriginal citizens. As in Foucault's (2009) analysis of the special pastoral nature of western governmentality, the banks' power is over a flock, is held to be beneficent, is taken on as a duty, and creates from the flock, individual customers and account holders. As part of their commitment to 'reconciliation', the shepherd is sacrificing his profits for the flock, and the flock for the individual while at the same time expanding the domain of its governmentality.

\section{The story of the consultancy}

Pondering our objects, I thought back about how we had been invited to undertake the evaluation. We had been told that another university had agreed to do the work, and after much delay, had pulled out. The Big Bank had contacted our university (the only one in the Northern Territory where the program was undertaken), our Office of Research had contacted the director of one of the research institutes, and she had handballed it to us. The Director, a colleague, was so far removed from both us and the two banks that it didn't worry her that we had no experience in program evaluation. We were keen mostly because of our commitment to sustainable livelihoods and cultures 'on country', and our desire to involve Aboriginal traditional knowledge authorities in academic research work. They needed their evaluation done (the final dot point in the Big-Bank-Small Bank partnering agreement to do with the Financial Literacy program was 'to support an independent evaluation of the program') and we needed the work and were experienced in on-the-ground cross-cultural consultancy work. John (a nonAboriginal colleague) and I went along to the Small Bank offices to negotiate the project. We had quite different discussions with the Small Bank General Manager, their Training and Development Manager, the Small Bank/Big Bank Financial Literacy Project Manager, and the Big Bank Head of Group Community Relations. They all wanted something slightly different, and we were already unconvinced, having read the background material, that the solution to Yolnu financial problems would be a package of financial literacy training. (We had both lived for twenty years on remote Yolnu communities.)

Sifting through the files on the university server, I find notes on some slightly tense negotiations with the senior management at Small Bank (ANZ-Traditional Credit Union, 2008), getting them to agree to allow us to report on two main focuses:

1. ... what had happened during the 18-month trial period of the Project. ... the effectiveness of the Project, experiences and perspectives of participants, and their recommendations for improvement 
2.... broader financial literacy issues and general Small Bank services.... the banking experience in communities and information regarding the future development of Small Bank services, products and communication materials

It didn't take long to detect some ambivalence on the part of the Aboriginal clients towards the Financial Literacy Program. That ambivalence was shared by the hapless young Aboriginal Financial Literacy educator who had been employed to deliver the program and met an unenthusiastic reception. Here is a typical entry from his field notes:

I have helped several helping them through and explaining each question and the meaning of things. But in all have explained to them that my role to help and assist them to better manage their monies, not to help them get into debt or claim payments that could get them in trouble. Most I referred to the institution or company to whom they have been dealing with, and informed them of the down sides that lie ahead. In this I have received a lot of flak for and have been asked what are you here for? Your (sic) not here to help us. These people mostly women in the community haven't spoken or even looked at me since....

He had left the job after only a few months.

When asked by our evaluation team what they felt about the Financial Literacy Program materials (the flip charts posters, etc.), most of the community members had no recollection of ever seeing them. But they were keen to give their feedback on the services they received, and to reflect upon the service in terms of their own use of money, resources and kin. And the Yolnu consultants, senior members of the community, but paid by us as consultants, were very keen to work with the community members to produce a coherent convincing report for the banks which represented the views of the community on the two agreed focus points.

Producing the report was quite a tricky process, where we (non-Aboriginal) academics worked with the Aboriginal consultants to come to agreement on what should be reported and how. They were learning how to produce a particular sort of object, and we were learning how to pitch a particular sort of argument (or a performance), honestly and persuasively.

After the report had been pulled together and delivered, we all invited the Small Bank staff to the University to discuss the findings and some ways forward for the program. We sat around the seminar room table with a new tablecloth, shared cups of tea and cakes and began to discuss what the consultants had heard in the three different communities they had visited. As the stories unfolded, the dislocation between the banks' and the community members' understandings of the fundamental requirements of financial literacy started to crystallise. The stories encoded in the financial literacy materials - to do with saving schemes, interest, time-payment, account options - were in some ways quite different from the stories of the Aboriginal clients.

As the stories of Aboriginal life unfolded, the program of Financial Literacy faded into the background. We heard stories of the complex exigencies of daily life on a remote community under strict government control. The Aboriginal clients did not resist the message of saving. It would be good, said one, for us all to have a 'Christmas Club' as the Financial Literacy trainers suggested, but what with the importunity of the extended family, demand sharing, the high cost of everyday goods, and the lure of the gambling circles $^{3}$, we never have a chance to save up for big purchases. We always wait for the big wins around the card circles to buy outboard motors or second hand Toyotas. 
When it comes to money business, it is clear that the remote community members are pretty savvy. It's not that money is a foreign thing to their culture. In fact it's precisely because money is an intrinsic part of their culture that it operates so differently. So what then, might Small Bank do to help their clients make best use of their 'financial products'? What we really need for our financial literacy, the consultants made clear, is immediate, free access to our account balances ('24/7') - a public ATM in each remote community centre would be good - and, for those people stuck in Darwin (the capital city) waiting for the money to fly home, the chance to swipe their cards at the ATM to find out whether their family has sent the money for the fare without paying $\$ 2$ per swipe. We also need good phone support for our banking needs. (There is an 1800 number but the records show that in one year there were over 7,000 missed calls.) The Yolnu in communities offered many very practical solutions.

As the Yolnu vision of financial literacy unfolded through the discussion, the discomfort of the credit union people increased. How would they report the complete failure of the Financial Literacy Program to the large funding bank? They started gently to raise a few objections, which bemused the Yolnu consultants. What worried the consultants was not so much (or at all) the fact that the bank didn't take on board the suggestions they were making for how Financial Literacy could be improved, but rather that they weren't accepting these suggestions in the spirit of good faith, and cooperation. The consultants had acted in good faith talking to the people around the card circles, and reporting back to the bankers. They had been paid properly, and so had the people they had interviewed. We at the university were being paid properly. The payments to the Yolnu consultants and co-researchers had ensured that we and they were working together in good faith.

Now it was time for the bankers, too, to listen carefully and in good faith, and respond to the 'findings'. But this was difficult for them. They had two problems: One, that the Yolnu don't understand how money should be used (they had poor levels of financial literacy); and two that we have no evidence of success to report back to the Big Bank. The Yolnu consultants on the other hand, have two parallel problems: The balanda (white people) don't understand how Aboriginal money is used; and there is no evidence of good will to report back to the community. The credit union people went away bemused. They showed no sign of discerning the complex knowledge practices through which the object of Financial Literacy had the effect of producing them as particular sorts of bank managers, trainers and community engagement staff. Maybe they felt that we had done a poor job of evaluating their program. There was never any sign of their taking on the consultants' recommendations.

\section{The governmentalities of money}

I had been reading Foucault's (2009) lecture on why and how to study governmentalities when I stumbled upon the Financial Literacy folder as I cleaned out my V: drive. I thought of the work that the consultants were doing to engage the bank officials in good faith. They began, as did Foucault, by moving outside of the 'institutional-centric' approach, looking at the overall technologies of power - their kin responsibilities, the tyrannies of distance, the poverty and the Emergency Intervention ${ }^{4}$, demand sharing and the avoidance of accumulation. They could see the banks and their Financial Literacy program as an effect of these complex technologies, which, at the same time, gave the strategies and tactics of Financial Inclusion concrete expression, intensifying and giving order to its governmentality. Then, the consultants found a way of decentering the Financial Literacy project in terms of its intended function, and replacing it with a clear regime of their own strategies and tactics implemented through the semi-formal faceto-face meeting with tea and buns in a university seminar room. Finally, (Foucault is still helping

4. Northern Territory National Emergency Response see http://www.aph.gov.au/Parliamentary_Business/Bills_Legislation/ Bills_Search Results/Result?bld=r2850 
me here), they refused the ready-made object (not here madness, delinquency or sexuality but financial literacy). They made no attempt to measure the banks practices and knowledge in terms of Financial Literacy, but told stories about how the changing worlds of money work in their remote lives constituted a field of truth that was the proper topic of discussion over tea and buns.

\section{Conclusion}

Returning to the task of cleaning out the V: drive, I came across another folder - this one called Health Literacy - containing the traces of a number of other research projects around such rubrics as health communication, health promotion, health interpreting, and health literacy. Here once again I could see how collaborative work with the consultants had led us to reconstitute the notion of Health Literacy as a function of a particular governmentality, not one of its effects. I found a definition of Health Literacy we had come up with:

The capacity to build and generate shared understandings about health, treatment and health services. This definition focuses upon both knowledge and the structures and processes through which agreed understandings and agreed ways forward are negotiated, produced and reproduced (Office of Aboriginal and Torres Strait Islander Health (OATSIH), 2010, p.9).

Putting together the two folders and the two literacies helps to show up the distinctive nature of the quiet ongoing work of re-thinking objects of governance. Looking through the lens of what Foucault called, the 'insubstantial and vague domain covered by a notion as problematic and artificial as that of governmentality' (2009, p.116), we can begin to see the quiet and subtle work of Aboriginal consultants (re)constituting the often false polity of the 'Aboriginal community' as an agentive civil society engaging with both big business and the institution of the university, and constituting them (and me) in unexpected and unexpectedly just ways.

\section{References}

ANZ. ANZ Indigenous Action Plan 2011/2014 Summary. Retrieved from http://www.anz.com.au/ resources/b/8/b88e62004bb3e854b47efec96010cd62/Indigenous_IAP.pdf?MOD=AJPERES

Christie, M., \& Young, M. (2011). The public problem of 'Aboriginal gambling': winning the struggle for an urban space, Australian Journal of Social Issues, 46(3), 253-272.

Foucault, M. (2009). Security, Territory, Population: Lectures at the College de France 1977-1978 (Vol. 4). New York, NY: Macmillan Publishers.

Leyshon, A., \& Thrift, N. (1995). Geographies of financial exclusion: financial abandonment in Britain and the United States. Transactions of the Institute of British Geographers, January, 312-341. Retrieved from http://scholar.google.com.au/citations?view_op=view_ citation\&hl=en\&user=THGyPdUAAAAJ\&citation_for_view=THGyPdUAAAAJ:9yKSN-GCBOIC

Northern Territory National Emergency Response. Retrieved from http://www.aph.gov.au/ Parliamentary_Business/Bills_Legislation/Bills_Search_Results/Result?bld=r2850

Office of Aboriginal and Torres Strait Islander Health [OATSIH], (2010, June). East Arnhem Land Client Health Education and Health Interpreting Scoping Report and Project Proposal [Commissioned by Charles Darwin University for OATSIH]. Retrieved from http://www.cdu.edu.au/centres/hl/pdf/ CHEI_SCOPING_STUDY_AND_REPORT_JUNE_2010.pdf 